\title{
DIGITAL TECHNOLOGY IN LABOR RELATIONS
}

\author{
Nayra A. Abuzyarova \\ The Institute of Legislation and Comparative Law under the Government of the Russian Federation, \\ Moscow, Russian Federation
}

Introduction: the emergence of such freelancing as remote labor meant the beginning of the process of the flexible virtual law formation. "Cloud computing" is coming into life. There appear the concepts of "working in the cloud" only in the virtual (digital) space, so the government program "Digital economy in the Russian Federation" of July 28, 2017, No. 1632-P adopted in the framework of the Decree of the President of the Russian Federation of May 9, 2017 provided the need for the formation of a comprehensive legislative regulation of relations arising in connection with the digital economy development. At the same time, it is specifically noted that the labor market should be based on its requirements in order to create productive employment. Methods: the methodological framework for this study is the methods of scientific knowledge, among which the main ones are the methods of consistency, analysis and comparative law. Results: the paper is devoted to the existing problems of the legal regulation of digital technologies in labor relations for the expedient and empirical updating of many legal norms, from which in the future it will be possible to start, change and supplement it, adhering to a fundamental change in labor relations in order to develop non-standard and fruitful employment. Conclusions: as a result of the conducted research it is established that in the Russian Federation the labor legislation regulating the electronic legal employment relations is fragmented and does not contain all the elements of the legal regulation. There is a need for the legislation on archive business in electronic form, the widespread introduction of electronic employment contracts, which can serve as the basis for the electronic personnel records management. The labor legislation should contain the provisions on the equivalence of an electronic labor contract to a written form.

Key words: digital economy, virtual jobs, freelancing, labor market, digital technologies, employment relations, electronic work books.

Citation. Abuzyarova N.A. Digital Technology in Labor Relations. Legal Concept, 2019, vol. 18, no. 3, pp. 26-30. (in Russian). DOI: https://doi.org/10.15688/lc.jvolsu.2019.3.4

УДК 349.2

Дата поступления статьи: 03.06.2019

ББК 67.405 .1

Дата принятия статьи: 20.06.2019

\section{ЦИФРОВЫЕ ТЕХНОЛОГИИ В ТРУДОВЫХ ОТНОШЕНИЯХ}

\author{
Найра Абдулкадыровна Абузярова \\ Институт законодательства и сравнительного правоведения при Правительстве РФ, \\ г. Москва, Российская Федерация
}

\footnotetext{
Введение: появление такого вида фриланса, как дистанционный труд, означало начало процесса фора мирования гибкого виртуального права. В жизнь вошли «облачные технологии», концепции «работ в обла尺े ке» исключительно в виртуальном (цифровом) пространстве. В настоящее время цифровые технологии в i трудовых отношениях и рынок труда в целях формирования продуктивной занятости опираются на требования Национальной программы «Цифровая экономика Российской Федерации» (утв. президиумом Совета ॠ при Президенте РФ по стратегическому развитию и национальным проектам, протокол от 04.06.2019 № 7), направленной на достижение цели, определенной Указом Президента РФ от 7 мая 2018 г. № 204 О национальных целях и стратегических задачах развития Российской Федерации на период до 2024 года», в части решения задач и достижения стратегических целей по направлению «Цифровая экономика». Методы: мето-

() дологическую основу данного исследования составили методы научного познания, среди которых основное
} 
место занимают методы системности, анализа и сравнительного правоведения. Результаты: данная статья посвящена существующим проблемам правового регулирования цифровых технологий в трудовых отношениях, которые вызваны кардинальными изменениями трудовых отношений в современный период. Выводы: в итоге проведенного исследования установлено, что в Российской Федерации трудовое законодательство, регулирующее электронные трудовые правоотношения, фрагментарно и не содержит всех элементов правового регулирования. Необходимо законодательство об архивном деле в электронном виде, повсеместное внедрение электронных трудовых договоров, которые могут служить основой электронного кадрового делопроизводства. Трудовое законодательство должно содержать положения о приравненности электронного трудового договора к письменной форме.

Ключевые слова: цифровая экономика, виртуальность рабочих мест, фриланс, рынок труда, цифровые технологии, трудовые отношения, электронные трудовые книжки.

Цитирование. Абузярова Н. А. Цифровые технологии в трудовых отношениях // Legal Concept = Правовая парадигма. - 2019. - Т. 18, № 3. - С. 26-30. - DOI: https://doi.org/10.15688/lc.jvolsu.2019.3.4

\section{Введение}

Интенсивное развитие цифровой экономики, появление искусственного интеллекта, который пока является метафорой, но уже работает, купля-продажа товаров по Интернету - все это говорит о цифровой трансформации всех сторон жизни общества и государства. Темпы цифровой трансформации сферы услуг нарастают, и можно ожидать, что уже к 2020 г. не менее $20 \%$ рабочих мест в стране будет полностью цифровизировано. Появление такого вида фриланса, как дистанционный труд, означало начало процесса формирования гибкого виртуального права.

В итоге работодатель будет вынужден делать ставку на производство в «облаке» и перейти к матричной структуре управления от классического иерархического управления, которая осуществляется посредством информационных технологий территориально распределенными проектными командами.

Из изложенного вытекает важный максимизирующий социальный вывод о необходимости кардинальной перестройки институциональных механизмов рынка труда, соответственно занятости, от которых зависит развитие экономики. Серьезного переосмысления требует система трудоустройства.

Сегодня уже ставится вопрос о принятии комплексного закона, регулирующего вопросы цифровой экономики. Некоторые эксперты указывают на необходимость принятия цифрового кодекса, а также закона об основах цифровой экономики.

Думается, что прежде всего необходима подготовка комплексной концепции право- вого регулирования цифровой экономики - определяющей развитие цифровой экономики на десятилетия, на долгосрочную перспективу.

\section{Развитие электронных технологий в трудовых отношениях}

С развитием дистанционного труда в России в жизнь входят «облачные технологии», возникают концепции «работ в облаке» исключительно в виртуальном (цифровом) пространстве.

По расчетам компании «Ростелеком» внедрение цифровых технологий в трудовые отношения через 4-5 лет принесет экономический эффект в 0,8-1,4 трлн руб. за счет роста производительности труда на 10-25\% и сокращения расходов на 10-20\%. В то же время не стоит забывать, что, когда речь идет о внедрении новых технологий в контексте среднесрочных и долгосрочных прогнозов, экономистам во многих случаях присущ избыточный оптимизм [4, с. 9].

Роботы стали не только реальными (умные заводы, беспилотные машины), но и виртуальными (программирование, алгоритмы, системы управления, искусственный интеллект).

Виртуальность рабочих мест с сетевым доступом ко всей необходимой информации из любого места, с любого устройства в перспективе может стать полноценной заменой стационарному компьютеризированному рабочему месту сотрудника, работающего по трудовому договору на условиях стандартной занятости.

Развитие цифрового человека с его умениями и цифровыми навыками становится основным трудовым капиталом. 
Исходя из этого возникает необходимость кардинальной перестройки институциональных механизмов рынка труда, от которых зависит развитие экономики.

Возникает вопрос: выгодно ли внедрение электронного делопроизводства для работников, занятых в продуктивной и неустойчивой занятости, для прекариата, для лиц, работающих в теневой экономике? Выгодно, поскольку после введения электронного делопроизводства станет меньше сотрудников, работающих по нескольким трудовым книжкам, а они у нас имеются, болеепрозрачными станут размеры получаемых заработных плат, в результате уменьшится децильный показатель оплаты труда, увеличится количество рабочих мест, вырастет заработная плата.

Следует констатировать, что в настоящее время группа в России $20 \%$ наиболее высокооплачиваемых верхних квинтилей работников владеет практически половиной средств из начисленной заработной платы, в то время как на долю наименее оплачиваемых работников приходится менее 60 \% общей суммы средств начисляемой заработной платы.

Наиболее важным индикатором, характеризующим динамику развития рынка труда, является скорость замещения старых рабочих мест новыми. По мнению одного из ведущих европейских экономистов П. Кахуки, в эффективных экономиках ежегодно должно создаваться $15 \%$ рабочих мест, из которых $1 / 3$ должно приходиться на вновь созданные компании, 2/3 - на уже существующие. При этом показатели ликвидации должны быть сопоставимо ниже. В России по результатам обследования на начало 2017 г. создается 5,9 рабочих мест, ликвидируется 6,0% [2].

На наш взгляд, не выдерживает критики предложение о введении электронных трудовых книжек для вновь принимаемых работников и сохранении трудовых книжек на бумажных носителях для лиц, уже работающих по таким трудовым книжкам, до 2025 г., хотя бы исходя из интересов национального прекариата и неустойчивой занятости, поскольку масса сотрудников работает по нескольким трудовым книжкам и говорить о продуктивной занятости в данном случае невозможно.
Сегодня готовы ли наши работники к глобальным переменам, связанным с внедрением цифровых технологий в трудовые отношения? Думается, что - да.

У нас в стране на рынке труда спрос на рабочую силу формируют прежде всего работодатели, составляющие в РФ $10 \%$ от состава работающего населения. Рынок труда в России характеризуется тем, что крупные предприятия аккумулируют 60 \% работников, а крупный бизнес большей частью уже организовал электронное делопроизводство на микроуровне, то есть в рамках отдельных фирм и компаний. Таким образом, 70 \% работающего населения, включая работодателей в России, достаточно хорошо знакомы с электронным делопроизводством, поскольку во многих компаниях кадровое делопроизводство ведется в электронном виде и параллельно в бумажном.

\section{Электронные трудовые договоры}

На сегодняшний день трудовое законодательство регулирует электронные трудовые правоотношения фрагментарно и не содержит всех элементов правового регулирования. Попытаемся выделить наиболее значимые из них. Сейчас уже не так важно, где живет работник. Все большую популярность приобретают дистанционные способы заработка. Численность дистанционных, сезонных работников, вахтовиков, а также занятых у работодателей-физических лиц - растет. Сегодня дистанционно, вахтовым методом и сезонно работают у нас в стране порядка 5-7 млн работников, - и практически все они не заключают трудовые договоры из-за удаленности от работодателей, тем самым пополняя ряды нелегальной занятости.

Обязательное заключение, изменение и прекращение трудового договора в письменной форме мешает бизнесу и самим работникам, поэтому переход на электронные трудовые договоры с названными работниками может стать пилотным вариантом повсеместного внедрения электронных трудовых договоров, которые могут служить основой электронного кадрового делопроизводства и являются одним из ключевых вопросов цифровой экономики в трудовом праве. 
Более того, следует учесть, что законодательство большинства развитых стран разрешает осуществление всех операций, связанных с трудовыми договорами, в электронной форме [3].

Трудовое законодательство должно содержать положения о приравненности электронного трудового договора к письменной форме, как это сделано, например, в Республике Таджикистан. При законодательном урегулировании этого вопроса следует ориентироваться на США и Китай.

При ныне действующем порядке разработки нормативных актов по отраслям могут встречаться нормативные акты с комплексным объектом воздействия, например правовые акты, принимаемые на стыке трудового и гражданского права. В таких случаях необходимо изменять критерии отбора объектов правового воздействия и создать системы норм межотраслевого характера.

Трудовой договор с дистанционными работниками утратил традиционно выделяемые свойства трудового договора, такие как выполнение работы лично и подчинение работника правилам внутреннего трудового распорядка, и содержит отдельные элементы гражданско-правового характера, тяготеющие к нестандартной занятости с использованием цифровых технологий.

В настоящее время руководство предприятий избавляется от перенакопления рабочей силы, устраняется аккумуляция избыточной численности работников. По этой причине возникает необходимость вырабатывать соответствующую российскую политику занятости, а также стратегии и тактики механизма регулирования российского рынка труда [1, с. 128], то есть необходимо в правовое поле ввести нормы права о нестандартной занятости и ее формах.

\section{Выводы}

При введении электронных трудовых договоров с дистанционными работниками можно разработать нормативный акт межотраслевого характера с учетом взаимодействия трудовых отношений с договорными правоотношениями в сфере гражданского права, тем более что в настоящее время в гражданском праве уже функционируют новые виды договоров, например Договор об электронном обмене дан- ными и пр. В случае же форсмента трудового законодательства надо будет вводить новую правовую категорию - «лица схожие с работниками», как это сделано в Германии.

Сегодня уже ставится вопрос о принятии комплексного закона, регулирующего вопросы цифровой экономики. Некоторые эксперты указывают на необходимость принятия цифрового кодекса, а также закона об основах цифровой экономики.

В заключение отметим, что в Российской Федерации прежде всего необходима подготовка комплексной концепции правового регулирования цифровой экономики, которая должна быть рассчитана на долгосрочную перспективу - на десятилетия.

На сегодняшний день важна разработка электронных технологий в кадровом делопроизводстве в масштабе всей страны - с устранением бумажной аналогии.

Необходимо законодательство об архивном деле в электронном виде, чтобы создать защищенный электронный ресурс для фиксации в нем всех данных о работнике. В таком случае отпадет необходимость в создании электронных трудовых книжек.

\section{СПИСОК ЛИТЕРАТУРЫ}

1. Абузярова, Н. А. Экономико-правовое регулирование российского рынка труда / Н. А. Абузярова // Журнал российского права. - 2018. - № 1. C. $128-137$.

2. Андреева, Л. Ю. Влияние цифровой экономики на формирование трендов на российском рынке труда / Л. Ю. Андреева // Л. Ю. Андреева, О. Т. Джемаев. Государственное и муниципальное управление. Ученые записки СКАГС. 2017. - № 3. - С. 25-32.

3. Куренной, А. Цифровая экономика России. Электронное делопроизводство трудовых отношений / А. Куренной, И. Костян, Г. Хныкин // ЭЖЮрист. - 2017. - № 37. - С. 10.

4. Шикарин, А. Цифровые дали / А. Шикарин, М. Климова // Эксперт Сибирь. - 2018. - № 34 (518). С. 8-11. - Электрон. текстовые дан. - Режим доступа: https://expert. ru/siberia/2018/30/tsifrovyie-dali. Загл. с экрана.

\section{REFERENCES}

1. Abuzyarova N.A. Ekonomiko-pravovoe regulirovanie rossiyskogo rynka truda [Economic and 
Legal Regulation of the Russian Labor Market]. Zhurnal rossiyskogo prava [Journal of Russian Law], 2016, no. 8, pp. 128-137.

2. Andreeva L.Yu. Vliyanie tsifrovoy ekonomiki na formirovanie trendov na rossiyskom rynke truda [Influence of Digital Economy on the Formation of Trends in the Russian Labor Market]. Andreeva L.Yu., Jumaev O.T. Gosudarstvennoe i munitsipalnoe upravlenie. Uchenye zapiski SKAGS [State and Municipal Management. Proceedings of the SKAGS], 2017, no. 3, pp. 25-32.
3. Kurennoy A., Kostyan I., Khnykin G. Tsifrovaya ekonomika Rossii. Elektronnoe deloproizvodstvo trudovykh otnosheniy [The Digital Economy of Russia. The Electronic Records Management Labor Relations]. EZh-Yurist [EzhYurist], 2017, no. 37, p. 10.

4. Shikarin A., Klimova M. Tsifrovye dali [Digital Dali]. Ekspert Sibir [Expert Siberia], 2018, no. 34 (518), pp. 8-11. URL: https://expert. ru/siberia/ 2018/30/digital-dali.

\section{Information about the Author}

Nayra A. Abuzyarova, Doctor of Sciences (Jurisprudence), Leading Researcher, Department of Economic and Legal Problems, Institute of Legislation and Comparative Law Under the Government of the Russian Federation, Bolshaya Cheremushkinskaya St., 34, 117218 Moscow, Russian Federation, abuzyar2013@yandex.ru,pasc@izak.ru,https://orcid.org/0000-0001-8668-4957

\section{Информация об авторе}

Найра Абдулкадыровна Абузярова, доктор юридических наук, ведущий научный сотрудник отдела экономико-правовых проблем, Институт законодательства и сравнительного правоведения при Правительстве РФ, ул. Большая Черемушкинская, 34, 117218 г. Москва, Российская Федерация, abuzyar2013@yandex.ru, pasc@izak.ru, https://orcid.org/0000-0001-8668-4957 